\title{
Role of Women Entrepreneurship in Economic Development in India
}

\author{
Shivam Gupta ${ }^{a^{*}}$, Ravi Maheshwari ${ }^{b}$ \\ a,bDepartment of Business Administration, S.R.K (P.G.) College, Firozabad, Agra (U.P.) India \\ Affiliated to Dr. B.R. Ambedkar University, Agra (U.P.) India \\ Email Id:shivam15shaly@gmail.com
}

\begin{abstract}
Entrepreneurship development among women is important for the achievement of broader development objectives such as growth with equity. Studies indicate that many women entrepreneurs are found working in difficult situations when compared to their male counterparts. Factors like political instability, poor infrastructure, high production costs and non-conductive business environment affect women entrepreneurs more than men. Limited access to key resources like land, credit, legal and socio-cultural environment also act as serious impediments. In the era of globalization changing pattern of trade and evolving technologies necessitate skill enhancement that many entrepreneurs in the continent are yet to possess. Women entrepreneurship must be molded properly with entrepreneurial traits and skills to meet the changes in trends, global markets and also be competent enough to sustain and strive for excellence in the entrepreneurial arena.

This paper presents a brief view of the role of women entrepreneurs in the economic development of our country.

Keywords: Women entrepreneurs, growth, infrastructure, production.
\end{abstract}

\section{PAPER/ARTICLE INFO} RECEIVED ON: 02/07/2019 ACCEPTED ON: 05/11/2019

Reference to this paper should be made as follows:

Shivam Gupta, Ravi

Maheshwari (2019), "Role of women Entrepreneurship in Economic Development in India", Int. J. of Trade and Commerce-IIARTC, Vol. 8, No. 2, pp. 336-340 


\section{INTRODUCTION}

Economic growth and development of any country are deter-mined by human, physical and financial resources. An economy can move on to higher levels of growth either by acquiring a larger quantum of the factors of production or through technical progress. The objective of any planned development is to develop human resources to their brimming utilization. Therefore, industrialization is one of the ways of bringing about socio-economic development in any country. The economic development of a nation is sparked largely by its enterprising spirit. The characteristic of enterprising emerges from the inter play of behavior and activity of special segment of the population known as entrepreneurs. For example, India's economy is today poised for a flourishing entrepreneurial activity. It is also known that a healthy business environment is an essential requirement for entrepreneurial growth.

\section{Objectives AND ReSEARCH Methodology}

\subsection{Objectives of Study}

1. Examine Role of Women Entrepreneurship

2. Identify the changing structure of Women Entrepreneurship and economic development.

3. To find out the nature of Women Entrepreneurship and its effects on economic development in India.

\subsection{Research Methodology}

Research methods can be classified in different ways, the most common distinction is between the quantitative and the qualitative approaches. (Myers). Quantitative approaches were originally used while studying natural sciences like: laboratory experiments, survey methods and numerical methods. A qualitative study is used when the researcher wants to get a deeper understanding on a specific topic or situation. Myers stated that the qualitative approach was developed in social sciences in order to support the researcher in studies including cultural and social phenomena. Sources included in the qualitative approach are interviews, questionnaires, observations, documents and the researcher's impression and reactions. The chosen approach is qualitative.

Qualitative research typically takes the form of in-depth interviews with a small number of respondents. These interviews may be done one individual at a time, or in groups. Individual interviews have the advantages of providing very rich information and avoiding the influence of others on the opinion of any one individual. Individual interviews are very expensive and time consuming, however, and as a result, it is not likely that any one research program will interview large number of individuals.

\section{CONCEPT OF WOMEN ENTREPRENEURS}

Women entrepreneurship has long been associated with concepts such as women empowerment and emancipation. Increasingly, it has also been marketed as crucial for increasing the quality of life of women in the developing world. Further, it has also been encouraged as way of making changes to the status-quo of women in the Muslim world and re-addressing the balance of power within the family unit. The benefits of women entrepreneurship are many and varied and have been researched in great detail in the past. The purpose of this re-search is to facilitate a discussion on how best to empower women using entrepreneurship. This will in turn help in the marketing of entrepreneurship as a tool for the female empowerment and emancipation. 
Women constitute almost 50 per cent of the world population. So the socio-economic participation of women at the international, regional, national and local levels means using significant potential resources more effectively. Moreover, it is noticeable that entrepreneurship development and empowerment are complementary to each other. Women empowerment depends on taking part in various development activities. In other words, the involvement of women in various entrepreneurial activities has empowered them in social, economic, culture and other related fields. It can be understood that women entrepreneurs have been making significant impact in all segments of the economy in the developed countries like Canada, United kingdom, Germany, Australia and the United States, etc.,

Women entrepreneurs engaged in business due to different push and pull factors which encourage women to have an independent occupation and stands on their own legs. For example, move towards independent decision making on their life and career is the motivational factor behind this urge. In other words, women entrepreneurs are persons who accept challenging roles to meet their personal needs and become economically independent. Besides, a strong desire to do something positive is an inbuilt quality of entrepreneurial women, who is capable of contributing values in both family and social life. The challenges and opportunities provided to the women of this digital and dynamic era are growing rapidly that the job seekers are turning into job creators. On the other hand, many women start a business due to some traumatic events, such as divorce, death of bread winner, sudden fall in family income, permanent adequacy in the income of the family etc.

The rising number of female business owners is currently a global trend especially in the developing countries. In the advanced market economies, women own more than 25 per cent of all business. Many people argue that women are 'pushed' rather than 'pulled' into business ownership Recent studies indicate that many women now actively choose self-employment, especially the younger women. Quite interestingly, women entrepreneurs can significantly contribute to poverty reduction, mobilisation of entrepreneurial initiatives and accelerating the achievement of wider socio-economic objectives. However, the contribution of women entrepreneurs depends on their performance, which, in turn, is affected by the underlying facilitators and barriers. Over the past two decades, women entrepreneurs have come to be recognised for their significant contributions to socio-economic development of their respective countries.

\section{ROLE AND CONTRIBUTION OF WOMEN ENTREPRENEURS IN INDIA}

In India, women dominate the micro enterprise sector both in rural and urban areas. According to the central statistical authority women account for close to 70 per cent of the micro enterprises in India are run by women. However, their participation in small, medium and large enterprises diminishes. Beyond the participating in productive activities such as agriculture, trade and industry, women have multiple roles in society. They participate in productive activities such as agriculture; they are responsible for caring for the family including the preparation of food, health care and education. Women need to balance this different role and therefore they are multitasked, managing their businesses alongside all other roles they are expected to perform. Women account for a larger share of the informal economy operators, as well as those running micro and small enterprises in India. MSME's make a significant contribution to the socio-economic

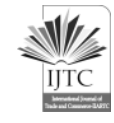

$-338-$ 
development of the country by way of supporting the people to earn money and make a contribution to family income, and by supplying basic goods and services for local consumption. However this contribution is not fully recognise or understand, and there is little in the way research or statistics to provide a broader understanding of women's experience as business owners, their contribution to economic development or the challenges they face in setting up, managing and growing their enterprise.

Women entrepreneurs are often described as 'survivalist' and dominate the low skill, low capital intensive and often informal and micro business. Women tend to focus on business that is a continuation of their domestic roles, such as the ser-vice sector. The potential for the growth of women's enterprises is said to below and is driven less by entrepreneurial drive than the need for survival. Women comprise 74 per cent of those employed in the micro enterprises sector. More than 65 per cent of all women in cottage $\backslash$ handicraft industries (micro enterprise) were engaged in processing food products and beverages.

\section{ECONOMIC CONTRIBUTION}

Women's economic activities contribute directly to growth and efficiency in dealing with informal business problems and poverty reduction is one of the main issues for policy makers

i) Capital formation: Entrepreneurs mobilize the idle savings of the public through the issue of industrial securities. Investment of public savings in industry results in productive utilisation of national resources. The rate of capital formation increases, which is essential for rapid economic growth.

ii) Improvement in Per capita Income: Women entrepreneurs in India have also been exploiting the opportunities. They convert the latent and idle resources like land, labor and capital into national income and wealth in the form of goods and services. They help to increase the country's net national product and per capita which are important yardsticks for measuring the economic growth.

iii) Generation of employment: Women entrepreneur in India are playing an important role in generating employment both directly and indirectly. By setting up small scale industries, they offer jobs to people.

\section{SOCIAL CONTRIBUTION}

Women entrepreneurs are also contributing towards improving the balanced regional development and improvement of living standards in the country.

i) Balanced Regional Development: Women entrepreneurs in India are to remove regional disparities in economic development. They set up industries in backward areas to avail of the resources concessions and subsidies offered by government.

ii) Improvement in living standards: With the setting up of small-scale industries, reduction of scarcity of essential commodities and introducing new products can be achieved. Women entrepreneurs in this country are producing variety of goods on a large scale and offering them at low rates, as a result, achieving improvement in the standard of life.

iii) Innovation: Innovation is the key to entrepreneurship. It implies that the commercial application of an invention. As an innovator, the entrepreneur assumes the role of a pioneer and an industrial leader. Entrepreneurs have contributed many innovations in the 
developing new products and in the existing products and services. All these have resulted in economic development by way of generating employment, more income etc.,

Other contributions: Women entrepreneurs are the main actresses in charging the culture of the society. In our country, women are workaholics and participate outside the house and develop the sense of independence and the like.

Thus women entrepreneurs in our country are directly or indirectly playing an important role in environmental protection, back ward and forward integration and are acting as charge agents, thus contributing to the economic growth of the country.

\section{CONCLUSION}

In the majority of women operate their medium and small enterprises under very adverse conditions. Not only is it difficult for them to find premises, find markets for their products, access information and credit, but they also have limited access to training especially in the rural areas. Their educational levels are low, they are responsible for all the domestic chores and they have to seek permission from their family members to travel to trade fairs or for training, even if they do want to grow their enterprises. Women entrepreneurs need to be better organised into women entrepreneurs Association which help identify higher potential business opportunities, develop markets for their products, improve product quality and marketing skills, practice good financial management and secure better premises.

\section{REFERENCES}

[1]. Das M. (1999), "women entrepreneurs from southern India: An exploratory study", Journal of Entrepreneurship, 8-147.

[2]. Deshpande S. and L.K Deshpande (1992), "New Economic policy and female employment", Economic and political weekly, 27.41:2218-225.

[3]. Eshetu B. and W. Zeleke (2008), "Women entrepreneurship in micro, small and medium enterprise, Journal of International Women's Studies, Nov-12.2:n.p

[4]. Government of India (2009-10), Economic Survey, New Delhi: Ministry of finance

[5]. Khanka S.S. (2001), Entrepreneurial Development, New Delhi's Chand and Co.

[6]. Mitra S., (2006), "Pattern of female employment in urban India: Analysing NSS Data 1983 to 1999-2000", Economic and political weekly, 41.48:5000-08.

[7]. Singh, Kamala (1992), Women entrepreneurs, New Delhi: Shish Publishing House New Delhi.

[8]. Sinha U.P. (2010), "Women Development and entrepreneurship in India in 21st Century: A Synoptic View" Women's link, 16.2:22-24, April-June. 